\title{
Newer Perspective in Neonatology—Need for Updating
}

\author{
Ballambattu Vishnu Bhat ${ }^{1}$ (I)
}

Received: 17 March 2021 / Accepted: 22 March 2021 / Published online: 7 June 2021

(C) Dr. K C Chaudhuri Foundation 2021

Neonatal mortality accounts for $53 \%$ of under-five mortality in India. Although mortality among infants before $28 \mathrm{~d}$ of life has reduced from 38 in 2000 to 23.5 per 1000 live births in 2017 , it still accounts for $20 \%$ of global deaths in this age group $[1,2]$.

Neonatology, like any other specialty, is undergoing rapid changes. Practicing neonatologists and Pediatricians need to keep themselves abreast with recent changes in the field in order to provide the best evidence-based practice. With this objectives in mind, the Editorial Board members of the Indian Journal of Pediatrics have decided to bring out a special symposium in Neonatology. I thank my co-editor Dr Sudhin Thayyil from Imperial College of London for his help and support in bringing out this symposium. We thank the authors for writing the topics within a short period of time. The topics have been carefully selected to cover important issues.

There are several studies on alteration in microbiome of the individual by the use of probiotics in the prevention and treatment of various conditions. Preterm infants have immature immune systems. They are more prone to necrotizing enterocolitis and sepsis, especially when exposed to hospital environment. The role of probiotics in the management of preterm infants has been discussed in detail by Patole et al. [3].

Respiratory distress is a common issue among newborn infants irrespective of maturity. It is more common among preterm and post-term infants. Many of these infants require supplemental oxygen and ventilator support. Noninvasive ventilation has become more popular not only because of its lower cost, effectiveness, and easy availability but also because it reduces postextubation problems. Preterm infants who had received noninvasive ventilation have reduced lung injury and bronchopulmonary dysplasia. Murki et al. have

Ballambattu Vishnu Bhat

drvishnubhat@yahoo.com

1 Department of Pediatrics and Neonatology and Division of Research, Aarupadai Veedu Medical College \& Hospital, Vinayaka Mission's Research Foundation, Pondicherry 607403, India discussed the various modes of noninvasive ventilation with their benefits and drawbacks [4].

Isolated inborn errors of metabolism are not very common but they become important issue collectively. It is important to recognize them early in life since many of them are treatable. Early diagnosis and appropriate treatment can reduce the morbidity and mortality. The outcome is better if these infants are treated in well-developed centers with adequate follow-up. Umamaheswari has discussed their clinical presentation, investigations to be undertaken, and treatment options available [5].

Nutrition of the infant, especially micronutrients are closely associated with immunity and infection among neonates. Zinc has several actions on the immune system. Zinc has both preventive and therapeutic value. Moreover, it is universally available at low cost. It can benefit as an adjunct to other modes of therapy in neonatal sepsis, especially among preterm and low-birth-weight infants. Newton et al. have discussed the benefits of zinc supplementation in the treatment of neonatal sepsis [6].

With advanced neonatal care, large number of very preterm and extremely low-birth-weight babies survive with increased respiratory and other morbidities. It is not just the survival but also the quality of life which is important. Unfortunately, the prevalence of cerebral palsy and bronchopulmonary dysplasia have not come down. There are several steps that the treating physician can take to prevent and reduce the occurrence of bronchopulmonary dysplasia. Shukla et al. have discussed steps for preventing and treating bronchopulmonary dysplasia [7].

The available knowledge is vast in the field of Neonatology. The authors and editors have tried their best to bring the available knowledge in the area to help the treating physician. This is the first part of the symposium and the second part will be published in the subsequent issue. I am sure that these reviews will benefit all those working in this field. Our best wishes for the untiring physicians striving to bring smiles to the tiny citizens and their parents.

\section{Declarations}

Conflict of Interest None. 


\section{References}

1. Kumar P, Singhal N. Mopping of neonatal and uner-5 mortality in India. Lancet. 2020;395:1591-3.

2. Godhino MA, Murthy S, Lakiang T, Puranik A, Nair SN. Mopping of neonatal mortality in India - a closer look. Indian J Community Med. 2017;42:234-7.

3. Deshmukh M, Patole S. Current status of probiotics for preterm infants. Indian J Pediatr. 2021. https://doi.org/10.1007/s12098-02103736-2.

4. Anne RP, Murki S. Noninvasive respiratory support in neonates: a review of current evidence and practices. Indian J Pediatr. 2021. https://doi.org/10.1007/s12098-021-03755-z.
5. Balakrishnan U. Inborn errors of metabolism - approach to diagnosis and management in neonates. Indian J Pediatr. 2021. https://doi. org/10.1007/s12098-021-03759-9.

6. Banupriya N, Bhat BV, Sridhar MG. Role of zinc in neonatal sepsis. Indian J Pediatr. 2021. https://doi.org/10.1007/s12098-021-03748-y.

7. Shukla VV, Ambalavanan N. Recent advances in bronchopulmonary dysplasia. Indian J Pediatr. 2021. https://doi.org/10.1007/s12098021-03766-w.

Publisher's Note Springer Nature remains neutral with regard to jurisdictional claims in published maps and institutional affiliations. 